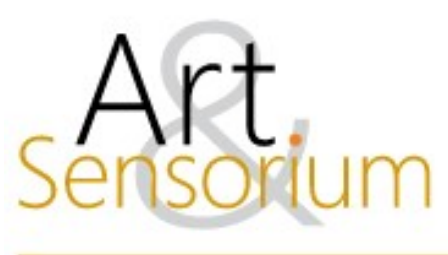

\title{
TÉCNICA KLAUSS VIANNA X COVID-19: UM OLHAR SOBRE O MOVIMENTO EM TEMPOS DE PANDEMIA \\ DOI: https://doi.org/10.33871/23580437.2020.7.2.153-163
}

Maria Augusta de Castilho ${ }^{1}$
Mariana Cavalcante de Brito ${ }^{2}$
Priscila Roberta Alves Lemos ${ }^{3}$

RESUMO: O presente artigo objetiva apresentar como a Companhia (Cia) de Dança Contemporânea da Universidade Federal de Mato Grosso do Sul (UFMS) realizou um trabalho de processo de criação em meio a situação de pandemia, provocada pelo Covid-19. O novo coronavírus alastrou-se por todo o globo e em pouco tempo, modificou toda a rotina das sociedades pelo mundo. Este trabalho foi dividido em três momentos: a apresentação da Cia de Dança; a situação da Pandemia e suas implicações para a cidade, universidade e cia; com enfoque nos estudos para a realização do processo de criação. A natureza da pesquisa é bibliográfica com revisão em livros, revistas, artigos, teses e dissertações; quanto ao tipo é descritiva. Já a abordagem é qualitativa e o método voltou- se ao indutivo, visto que é uma forma de argumentação utilizada a fim de se chegar a uma conclusão após um específico raciocínio. Firma-se para referências conceituais a autora Jussara Miller (2017), com seu trabalho de sistematização da Técnica Klauss Vianna (TKV), o qual embasa todo o processo de criação em dança da Cia. Verificou-se ainda a relação do tópico - a presença da TKV, com a atual situação da pandemia.

Palavras-chave: Técnica Klauss Vianna; Cia de Dança Contemporânea; Processo de Criação; Presença; Covid-19.

\section{TECHNIQUE KLAUSS VIANNA X COVID-19: A LOOK AT MOVEMENT IN TIMES OF PANDEMIC}

\begin{abstract}
This article aimed to present how the Contemporary Dance Company (Cia) of the Universidade Federal de Mato Grosso do Sul (UFMS) realized a creative process in the midst of a pandemic situation, caused by Covid-19. The new coronavirus has spread across the globe and, in a very short time, has changed the whole routine of societies around the world. This work was divided into three moments: presentation by Cia of Dance, Pandemic situation and its implications for the

\footnotetext{
${ }^{1}$ Pós-doutora em Linguística (2000) e Doutora em Ciências Sociais - História do Brasil (1997), ambas pela Universidade de São Paulo (USP). Atualmente é professora no Curso de História e no Mestrado em Desenvolvimento Local da Universidade Católica Dom Bosco (UCDB), sendo também responsável pelo Laboratório de História. 0000-0001-52353164.maugusta@ucdb.br

${ }^{2}$ Mestranda em Desenvolvimento Local (UCDB), Especialista em Dança e Expressão Corporal pelas Faculdades Integradas de Cassilândia (FIC), Graduada em Educação Física (UFMS). 0000-0002-7473-562X. maricbritoufms@gmail.com

${ }^{3}$ Especialista em Dança e Expressão Corporal (FIC), Graduada em Educação Física (UFMS). Graduanda em História (UFMS).0000-0002-8983-5244. prirobertalemos@hotmail.com
} 
city, university and Cia, focusing the studies to carry out the creation process. The nature of the research is bibliographic with review in books, magazines, articles, theses and dissertations, the type is descriptive. The approach is qualitative and the method has turned to the inductive, since it is a form of argument used in order to reach a conclusion after a specific reasoning. The author Jussara Miller (2017) signed up for conceptual references, with her work of systematizing the Klauss Vianna Technique (TKV), which bases the entire process of creation in dance by the Cia. The relationship of the topic - the presence of TKV, with the current situation of the pandemic.

Keywords: Klauss Vianna Technique; Contemporary Dance Company; Process of creation; Presence; Covid-19.

\section{TÉCNICA KLAUSS VIANNA X COVID-19: UNA MIRADA AL MOVIMIENTO EN TIEMPOS DE PANDEMIA}

Resumen: El presente artículo tiene como objetivo presentar cómo la Compañía (Cia) de Danza Contemporánea de la Universidade Federal de Mato Grosso do Sul (UFMS) realizó un trabajo de proceso de creación en medio la situación de pandemia provocada por el Covid-19. El nuevo coronavirus se ha extendido por todo el globo y, en poco tiempo, ha cambiado toda la rutina de las sociedades por el mundo. Este trabajo fue repartido en tres momentos: presentación de la Cia de Danza, la situación de la Pandemia y sus implicaciones para la ciudad, universidad y cia, centrándose en estudios para llevar a cabo el proceso creativo. La naturaleza de la investigación es bibliográfica con revisión en libros, revistas, artículos, tesis y disertaciones, el tipo es descriptivo. El enfoque es cualitativo y el método se ha convertido en inductivo, ya que es una forma de argumento que se utiliza para llegar a una conclusión después de un razonamiento específico. La autora Jussara Miller (2017) se apuntó a referencias conceptuales, con su trabajo de sistematización de la Técnica Klauss Vianna (TKV), lo cual es la base de todo el proceso de creación en danza de la Cia. La conexión del tópico la presencia con la situación actual de la pandemia.

Palabras clave: Técnica Klauss Vianna; Compañía de Danza Contemporánea; Proceso de creación; Presencia; Covid-19.

\section{Introdução}

Com início das atividades da Cia. de Dança Contemporânea da UFMS previstas para abril de 2020, a sociedade é surpreendida com uma onda de coronavírus que já ocasionou 23 milhões de pessoas contaminadas e 806 mil mortes em todo o mundo até o presente momento (Boletim Epidemiológico/Governo Federal/2020). O contágio por meio de contato com superfícies e/ou outras pessoas contaminadas, apenas aumenta e enquanto não há uma vacina para proteger a população, foram tomadas diversas medidas para amenizar a proliferação do vírus e possibilitar que a sociedade pudesse continuar com suas ocupações, afazeres ou incumbências no seu dia a dia.

Uma das medidas adotadas em diversos países, inclusive em algumas regiões do Brasil, como no caso de alguns setores da sociedade de Campo Grande - MS, foi o isolamento social, ou seja, separar os indivíduos do convívio diário. Na UFMS, foi instituído o trabalho remoto, situação em que os servidores e acadêmicos passaram a realizarem trabalho, estudos e demais atividades em suas residências de forma virtual.

O estudo, objetivou evidenciar como a Cia. de Dança Contemporânea da UFMS realizou um trabalho de processo de criação em meio a situação de pandemia, provocada pelo Covid-19. O diretor, coreógrafo e bailarino Ricardo Scheir (2012, p. 32), explica que "a essência da coreografia vem da verdade. Verdade na história ou na não história, verdade no movimento ou no não movimento". Pensando nisso e em como o novo coronavírus alastrou-se por toda sociedade afetando a convivência e modificando relações e rotinas pelo mundo, a Cia. reorganiza seu planejamento de atividades e 
encontrou nesta situação de pandemia um novo olhar sob a perspectiva de processos de criação em dança. Assim, houve os estímulos de Wachowicz (2008, p.120), asseverando que:

Os modos como as coisas no mundo se conectam e interagem formando estruturas; as possibilidades de relações que essas estruturas podem estabelecer e que o importante é compreender como essas relações estão arranjadas, ou seja, qual o padrão lógico que rege a organização de fenômenos.

As possibilidades que podem ser ocasionadas nesse momento completamente desconhecidas por todos, são na verdade oportunidades de descobertas para o corpo, para o movimento, para a dança e para a cena contemporânea. A Cia. de Dança Contemporânea da UFMS, como o próprio nome diz, busca seguir essa vertente e, portanto, tem tido a oportunidade de sentir na pele o significado real do que vem a ser contemporâneo. Wachowicz (2008, p.120), explica que;

O Contemporâneo, cujo significado é o que vive na mesma época, não teria sentido se não apresentasse novos paradigmas. Trazer novas propostas é propriedade do contemporâneo, mas nem sempre isso é habitual. [...], entendo que é possível contribuir para minimizar o desconforto que se experimenta ao deparar-se como uma nova proposta de pensar a dança. E, além disso, possibilitar um melhor entendimento do olhar da plateia para o palco onde artistas contemporâneos apresentam suas criações, em outras palavras, palcos onde se apresentam possibilidades diferentes de organizações de pensamentos.

O Covid-19 apresentou a este grupo da universidade uma nova proposta, na qual foi possível, saírem de suas zonas de conforto sobre o que acreditavam ser dança contemporânea e aprofundar questões antes desconhecidas pelos participantes, como possibilidades de estar presente e ter consciência do seu próprio movimento e deste, no espaço em que se encontra.

Outro aspecto conjuntamente é essa questão da utilização da tecnologia, em virtude do afastamento do convívio presencial, fazendo com que fosse imprescindível a utilização de computadores e da internet, que já vinha sendo utilizada para o auxílio de inovações nos modos de criação, mas que na situação atual, se fez extremamente necessária. Katz (2002, p. 12) observa que "Merce Cunningham, um dos mais importantes coreógrafos de toda a história da dança, entusiasmou-se pela descoberta do computador como um instrumento de criação".

Uma questão muito interessante sobre Cunningham, explica Katz (2002, p.12) é que:

Ao deixar de criar na forma habitual de produção e transmissão de conhecimentos em dança (improvisações com os bailarinos ou ensino de coreografia tendo o corpo do criador como modelo, seja em demonstração prática do movimento, seja em descrições orais), ele deixou de lado o movimento enquanto propriedade de um corpo e passou a focá-lo de outro modo, dando proeminência à questão do acesso ao movimento.

A natureza da pesquisa é bibliográfica com revisão em livros, revistas, artigos, teses e dissertações; quanto ao tipo é descritivo, com uma abordagem é qualitativa. O método utilizado foi o indutivo, visto que é uma forma de argumentação utilizada a fim de se chegar a uma conclusão após um específico raciocínio.

A primeira parte da pesquisa, apresenta a Cia. de Dança Contemporânea da UFMS a partir dos últimos trabalhos realizados e do cronograma de atividades previstos para sua execução em 2020 . O segundo

R. Inter. Interdisc. Art\&Sensorium, Curitiba, v.7, n.2, p. 153 - 163 Jul.- Dez. 2020 
tópico discorre sobre a pandemia pelo covid-19 e suas consequências em Campo Grande - MS, Universidade Federal e a Cia. de Dança, que representa esta instituição, dando base para o fechamento, destinado a descrição do processo de criação de um novo trabalho da Cia. nesse período descrito, elencando o tópico lúdico - Presença como suporte de aprofundamento da TKV.

\section{A Cia de Dança Contemporânea da UFMS}

A Cia. de Dança Contemporânea da UFMS surgiu em 2019 a partir dos estudos e ações do Núcleo de Estudos em Dança e Movimento (NEDeM). Criado em 2009, o NEDeM tinha como principais ações uma escola de dança que oferecesse aulas de diversos estilos de dança à comunidade e a realização de alguns grupos de estudos sobre a dança em geral ou algum estilo específico. Pensando em uma proposta corporal somática que pudesse contemplar diversos corpos, independente do estilo de dança que praticasse, iniciou-se em 2017 um grupo de estudos voltados para a Técnica Klauss Vianna (TKV).

A técnica do coreógrafo brasileiro é voltada a percepção corporal como um todo, para todos e em todas as situações, não somente para a dança e sim para a vida, sendo "um trabalho de observação e pesquisa das estruturas do corpo e do movimento humano" (MILLER, 2007, p. 15). A base desses estudos é o livro "A Escuta do Corpo - a sistematização da Técnica Klauss Vianna” de Jussara Miller (2007), resultado da dissertação de mestrado sobre seus estudos e práticas da TKV, visto que a autora teve aulas tanto com Klauss, quanto com seu filho, Rainer Vianna, que iniciou a sistematização da técnica.

Em 2017 e 2018 foi realizado um grupo de estudos teórico e prático da TKV com alguns participantes do NEDeM, porém em 2018, no $1^{\circ}$ Encontro de Coreógrafos das Universidades Federais (UF's) foi que surgiu a ideia de formar a Cia. $\mathrm{O}$ evento com a participação dos representantes das instituições do AM, MG, MS e PR foi pautado pela realização de trocas de experiências e reflexões sobre o papel do coreógrafo na instituição e a dança nas UF's, via seus componentes, verificou a necessidade de expandir os estudos, tanto nos campos teórico e prático, como principalmente de forma artística.

Para finalizar este evento, foi possível realizar a vinda da autora, professora e bailarina Jussara Miller, que com um workshop da TKV e apresentação de seu espetáculo "Nada Pode Tudo", reforçou os estudos anteriores e deixou mais evidenciado a projeção para os próximos trabalhos, utilizando a referida técnica, e que em pouco tempo, culminaria com a criação da Cia.

Após aprovação do projeto da Cia. de Dança no Programa de Extensão Universitária da UFMS (EXT, 2019), foi lançado o edital de seleção de bailarinos (Figura 1) composto de três fases: $1^{\mathrm{a}}$ fase inscrição e envio de currículo artístico, $2^{\mathrm{a}}$ fase - aula prática e $3^{\mathrm{a}}$ fase - entrevista. Após a análise do currículo e os cumprimentos dos pré requisitos previstos no edital, os aprovados na $1^{\mathrm{a}}$ fase realizaram uma aula prática, conduzida pela coreógrafa da UFMS e coordenadora do NEDeM, acompanhada de uma banca composta por três profissionais da área da dança que possuíam um roteiro a ser observado pelos candidatos. Ao término da aula, a banca e a coreógrafa realizaram reunião e discutiram os pontos observados e que apresentavam os requisitos solicitados para os concorrentes. 


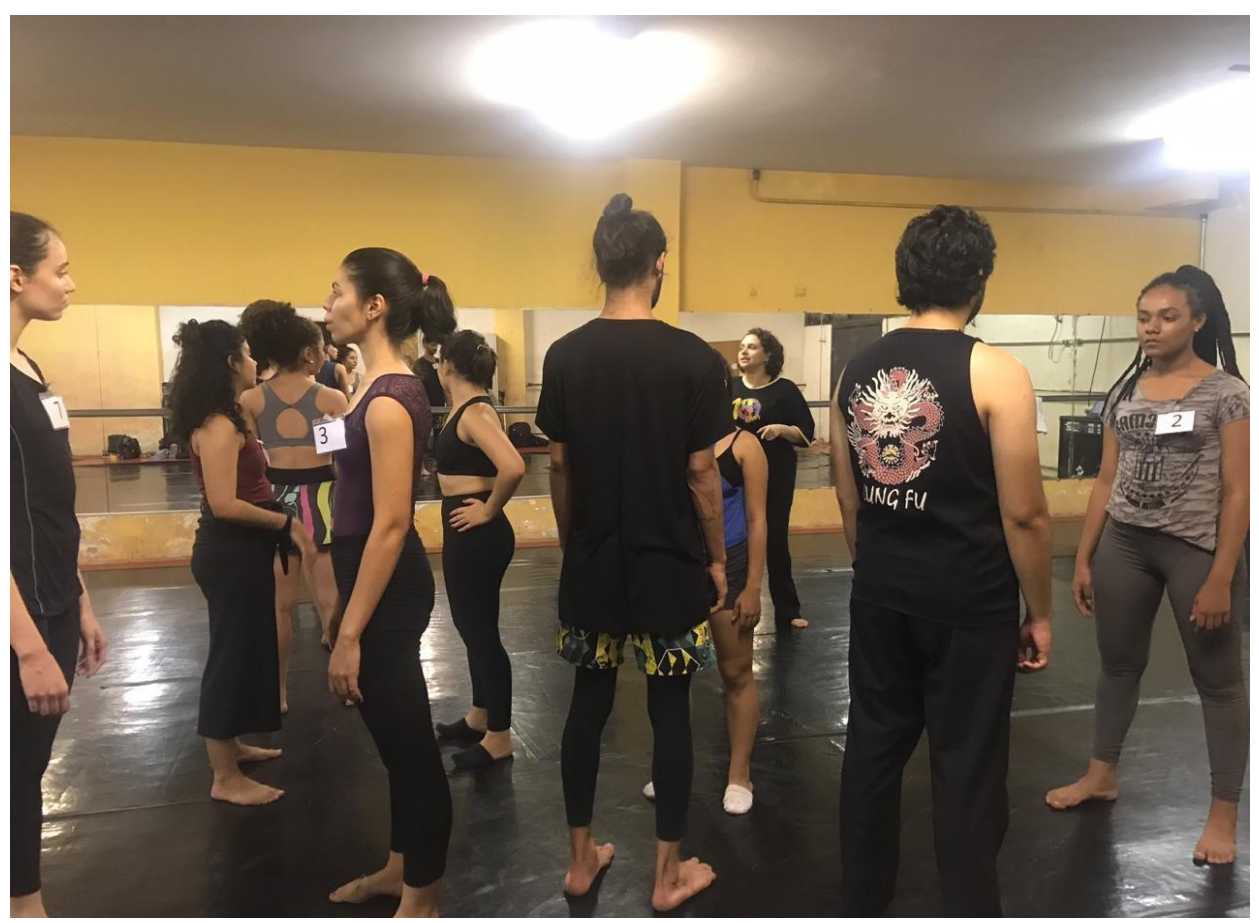

Figura 1. Seleção Cia de Dança Contemporânea Fonte: Arquivo da Cia UFMS, 2019.

Os aprovados na $2^{\mathrm{a}}$ fase realizaram entrevista com a coreógrafa e a assistente sobre o interesse e disponibilidade do candidato de participar da Cia. Ao finalizar o processo seletivo foram iniciadas as atividades da Cia. de Dança Contemporânea da UFMS em setembro de 2019 com 10 integrantes.

As aulas eram realizadas duas vezes na semana, composta por preparação física, estudos e dinâmicas da TKV, além, de estudos e dinâmicas de composição coreográfica. As atividades desenvolvidas semanalmente, tinham como objetivo apresentar a Cia. como seu primeiro trabalho relacionado ao tema anual da instituição: - os 40 anos da federalização da instituição. Para isso, na parte de composição coreográfica, foram realizados estudos com base no livro: - "As duas histórias da Universidade" de João Pereira da Rosa (1993), primeiro reitor da UFMS, o qual relata todo o processo de instituir um sistema estadual de educação superior na cidade até os primeiros anos de federalização da instituição, além de textos e imagens de arquivos da UFMS.

A preparação física foi desenvolvida para o grupo no geral para atender as necessidades da coreografia, entretanto, houve orientação para que cada integrante realizasse uma preparação específica de acordo a suas necessidades como complemento. Vale ressaltar que a preparação física e suas orientações foram realizados por profissionais de educação física integrantes da equipe da Cia. $\mathrm{Na}$ TKV foi realizado um trabalho de despertar do corpo, de conscientização de suas possibilidades e limites, evitando dessa forma, lesões e melhorando posturas. Foram 3 meses, 24 encontros até a estreia do espetáculo ID.40 como resultado desse processo inicial da Cia.

A formação da Cia. foi mantida até o final de fevereiro de 2020, com encontros e ensaios para atender ao convite da Pró Reitoria de Extensão, Cultura e Esporte (PROECE) de apresentar o ID.40 na abertura do evento de acolhimento aos calouros da UFMS. Após esse evento seria iniciado o cronograma 2020 da Cia. começando com uma nova seleção de candidatos, no qual os antigos integrantes teriam que realizar igualmente o processo seletivo, e para ingresso de novos participantes, previsto para lançar o edital de seleção no final de março, da mesma forma realizada no ano anterior. As aulas seriam de segunda a quinta no período noturno, com divisão das aulas novamente em preparação física, composição coreográfica e TKV, com ênfase nos estudos da técnica. $\mathrm{O}$ desenvolvimento das atividades ocorreria de abril a dezembro, com previsão de um resultado a ser 
apresentado no Festival Mais Cultura da UFMS no final de outubro/2020, juntamente com outras participações culturais e artísticas da instituição.

\section{COVID-19 e suas consequências para a Cia UFMS}

Sabendo que o contagio do corona vírus vem provocando um aumento brusco e demasiado em hospitalizações, no Brasil assim como em várias regiões do mundo tem sido tomadas medidas para amenizar a proliferação do vírus, visto que o sistema de saúde não possui condições para atender a uma demanda tão grande e crescente a cada dia. Neste contexto, a Universidade Federal de Mato Grosso do Sul (UFMS), de acordo com determinação administrativa interna e acompanhando a orientação e os protocolos estabelecidos pela Secretaria Estadual de Saúde do MS, Ministério da Saúde e Ministério da Educação se adaptou as consequências da pandemia e procurou executar o isolamento social da cidade universitária.

Ao visar a proteção da comunidade acadêmica - estudantes, servidores, estagiários, colaboradores terceirizados, cidadãos atendidos pela instituição e sociedade em geral, a instituição elaborou um plano de contingência, e que segundo a UFMS (2020, p. 5): "é um instrumento de gestão utilizado para ordenar e planejar as ações das organizações em situações específicas de crise". Sendo assim, uma "valiosa ferramenta [...] na implementação de medidas administrativas, acadêmicas e comunicacionais que buscam prevenir e/ou mitigar os efeitos dessa ameaça, foram implantados" (UFMS, 2020, p. 5). Ao traçar essas diretrizes para toda a universidade, objetivou-se proteger a comunidade e desenvolver instrumentos e serviços, como destaca o documento, a seguir,

Em prol da sociedade brasileira e apoiando as ações de saúde municipais, estaduais e federal, por meio de sua infraestrutura e equipe especializada, e promovendo a conscientização e o enfrentamento adequado frente a COVID-19, aliado a manutenção das atividades administrativas e acadêmicas, respeitando-se os normativos legais vigentes. As medidas adotadas por este Plano de Contingência dividem-se em três dimensões interdependentes: 1) Medidas de Cuidados com as Pessoas; 2) medidas de Atividades Acadêmicas; e 3) Medidas de Comunicação [...] (UFMS, 2020, p. 7)

Dentre as Medidas de Cuidados com as pessoas, foram elaborados 13 itens, sendo que 3 destes se relacionam com os objetivos do estudo, a saber:

6.1.4 - Adiar a realização de todos os eventos internos e externos, nacionais ou internacionais, organizados pela UFMS, independentemente do número de pessoas.

6.1.5 - Manter as atividades administrativas em pleno funcionamento, por meio da modalidade de teletrabalho, [...].

6.1.7 - Suspender todos os atendimentos de programas e projetos de extensão e de prestação de serviço à comunidade externa oferecidos pela UFMS, incluindo Clínicas-Escola, Farmácia-Escola, Clínica Odontológica, EMAJs, Museus, Fazenda Escola, Hospital Veterinário, Clínicas de Psicologia, entre outros (UFMS, 2020, p. 7).

Com o adiamento dos eventos e suspensão do atendimento de todos os programas e projetos presenciais, servidores foram encaminhados para realizarem trabalho remoto, ou seja, os trabalhos 
administrativos deveriam ser realizados de suas residências, de forma virtual, dada a gravidade e o alcance de contaminação do vírus.

Nessa situação a Cia. de Dança Contemporânea da UFMS, precisou interromper o seu cronograma de atividades no final de março/2020, ficando inicialmente a espera de atualizações da instituição para que pudesse retornar às suas ações em seu espaço dentro da instituição.

Em um primeiro momento, o representante da universidade determinou um período de isolamento em torno de 30 dias, os quais a comunidade acadêmica realizasse suas atividades administrativas a distância, todavia, antes de completar esse prazo, o tempo foi prorrogado por mais períodos, até que não se programou mais o retorno.

Acompanhando as notícias globais e determinações no país, estado e em Campo Grande - MS, observou-se que com o agravamento da situação, as atividades presenciais poderiam não retornar imediatamente, conduzindo a equipe da Cia. de dança a se reunir por meios digitais, para reavaliar o cronograma e suas atividades.

\section{Processo de criação coreográfica da Cia UFMS em meio a pandemia}

Com a paralisação de todas as atividades de atendimento presencial à comunidade interna e externa da IES, foram suspensas sem previsão de uma data e forma segura de retornar. O planejamento da Cia. foi revisto para que o trabalho desenvolvido no ano anterior não perdesse o foco e adaptou meios para seguir a proposta. Sem poder realizar a seleção presencial e percebendo que uma seleção virtual não atenderia no momento as necessidades de corpo disponíveis para o estudo da TKV, optou-se por entrar em contato com os integrantes da Cia. UFMS do ano de 2019 - tendo em vista, que a equipe de trabalho já conhecia os corpos, habilidades e dificuldades desse grupo - que tivesse interesse e disponibilidade para a Cia. com o momento atual e com a nova forma de trabalho. Retornando as atividades em 27 de abril/2020, com 05 integrantes, se reuniram às terças e quintas, no período noturno, via a plataforma Google Meet.

Esta plataforma profissional é disponibilizada para os servidores da instituição, possuindo mecanismos de gravação dos encontros e acesso ao Aplicativo Classroom, onde são inseridas as atividades solicitadas (textos e vídeos). O celular tornou-se essencial, tanto para as reuniões, quanto para as gravações de atividades, experimentações e trocas gerais de informações entre os participantes.

A preparação física iniciou de forma geral em ambos os encontros semanais no primeiro mês, para um novo despertar do corpo, após um período dos integrantes estarem sem atividade física e adaptação do espaço disponível de cada um em suas residências.

Posteriormente, foi iniciado um programa de treino e orientação individual para cada integrante para atender as necessidades de cada um, a ser realizado em período diferente dos encontros noturnos. Às terças foram direcionadas para estudos teóricos da TKV e outros textos de apoio, focando no tópico corporal - Presença. Às quintas, foram direcionadas para as práticas de dinâmicas e experimentações dos estudos de terça. Além dos encontros virtuais e do treino físico individual, foram realizadas atividades durante a semana de produção de textos e vídeos relacionados aos estudos que eram apresentados e discutidos nos encontros. Ao todo, foram 20 encontros até o primeiro resultado desses estudos.

Conforme Duenha e Nunes $(2017$, p.100), a presença é um "termo caro à dança, ao teatro e à performance, com pauta garantida em processos pedagógicos, compositivos e dramatúrgicos". Nesse diapasão, durante o processo com a Cia. foram realizadas diferenciadas formas de estímulos, que auxiliassem a compreensão desse tópico lúdico, proposto por Jussara Miller em seu livro a Escuta do 
Corpo, o qual embasou os estudos da Cia. de Dança Contemporânea da UFMS. No quadro 1 verificase quais foram esses estímulos.

\begin{tabular}{|l|c|}
\hline \multicolumn{1}{|c|}{ Estímulos } & Ocorrência \\
\hline 1.Leituras & 3 \\
\hline 2.Análises e discussões dos textos & 4 \\
\hline 3. Experimentações individuais (tarefas) & 6 \\
\hline 4.Preparação Física & 10 \\
\hline 5.Dinâmicas baseadas na TKV & 10 \\
\hline 6.Apontamentos sobre as experimentações práticas & 10 \\
\hline 7.Estudos de anatomia (ossos e músculos) & 2 \\
\hline 8.Produção de textos & 2 \\
\hline 9.Gravações & 3 \\
\hline
\end{tabular}

Quadro 1. Estímulos oferecidos para desenvolver o tópico presença

Fonte: Elaborado pelas autoras (2020).

Foi utilizado, um capítulo do livro - tópico lúdico - presença da autora Miller (2007) e 2 textos: abordagens somáticas do corpo na dança do autor Vieira (2015) e Presença que não se Faz Só: potências de afeto no ato de com-por entre corpos, das autoras Duenha e Nunes (2017), ambos da Revista Brasileira de Estudos da Presença.

A ideia foi de trazer indagações a cada participante do processo, incluindo não apenas os bailarinos, assim como direção e equipe da Cia. Surgiram questões: - 1 - como são as propostas de Duenha e Nunes (2017, p. 100); 2 - "o que é presença? 3 - Como ter presença ou estar em estado de presença? 4 - Como manter a atenção e convocar o engajamento dos corpos nas ações propostas?"

Nesta proposta, a Cia. de Dança após as leituras dos textos, realizou análises e apontamentos que pudessem ser discutidos nos encontros, o que foi realizado em quatro momentos. Cada participante ficou responsável por se aprofundar em partes do texto, sendo observado que o assunto pode trazer diferentes entendimentos e perspectivas.

Durante 10 encontros foram organizadas propostas de sensibilização embasadas pela TKV, com o objetivo de auto-observação, conduzida pelos sentidos, como assinala Miller (2007, p. 59): - “o despertar sensorial, que ampliará o sentido sinestésico resultando em uma presença: o estar presente aqui e agora". Estes momentos sempre foram iniciados com os bailarinos deitados no chão, em decúbito dorsal, braços abertos e palmas das mãos para cima, pois segundo Miller (2017), o chão é um aliado nesse trabalho de percepção do corpo.

Após cada um desses encontros de sensibilização foi solicitado aos bailarinos, que apontassem suas impressões, e comparações de como estavam antes e após as dinâmicas, podendo trazer ainda, relações com os textos que leram, e com o que já haviam visto até então. Jussara Miller (2017, p. 22), explica que a intenção do trabalho não se reduz ao "acúmulo de habilidades corpóreas, mas envolvem o pensamento do corpo, que é movimento, sentindo-o e assistindo-o, tornando-se, dessa forma, um espectador do próprio corpo". Portanto, esse momento em que os bailarinos informaram suas 
sensações, promovendo ainda, não só a consciência do que fizeram e fazem, mas também, dar continuidade dessas sensibilizações, em busca de uma melhoria da qualidade da dança e da autoestima de cada bailarino.

Em outros 6 momentos foram solicitados que fizessem atividades de experimentações de movimentos durante a semana, quando não estivessem nos encontros. Essas atividades eram baseadas nas dinâmicas da TKV que eles vivenciavam nas aulas, porém, deveriam ser feitas por cada um, em algum momento do seu dia sozinho. Poderia ser inclusive, em momentos em que estivessem deitados na cama, ou na hora do banho, ou em alguma hora do dia em que pudessem se auto perceberem.

Partindo para os estudos sobre anatomia, foram visados ossos e músculos. Percebe-se que muitas pessoas não têm conhecimento da composição do próprio corpo, incluindo bailarinos, como se pôde verificar em aulas do ano anterior, uma falta de conexão anatômica com o próprio corpo, e partindo do princípio da Técnica fundamentada por Miller (2007, p. 59) é que " o corpo é nosso instrumento, e [...] que antes de saber tocar um instrumento é necessário conhecê-lo. Não existe dança se não houver primeiro corpo".

Para iniciar, a Cia. dever-se-ia elencar 5 ossos e 5 músculos, os quais cada indivíduo observasse que utilizava muito durante o seu dia, deveriam ainda, observar a estrutura e que tipo de movimentos cada uma dessas estruturas era capaz de realizar, trazendo os nomes e suas considerações para a próxima aula. Após essa apresentação, foram demonstrados por meio de figuras ilustradas, partes de cada segmento do corpo. Finalizando com uma dinâmica de massagear iniciando os pés e fazendo o reconhecimento dos ossos e músculos, terminando no topo da cabeça.

Uma atividade que foi fundamental para iniciar esse processo foi solicitada no primeiro encontro, em que os integrantes escrevessem sobre o momento que cada um estava vivendo, os desafios dessa nova rotina e do COVID. Os textos foram enviados à equipe da Cia. para análise antes do segundo encontro, no qual cada um compartilhou seu momento. Após a expressão de cada integrante houve uma discussão coletiva da situação e possíveis soluções para amenizar a passagem dessa fase.

Nessa primeira atividade, realizada com 45 dias de quarentena, a maioria expressou que nas primeiras semanas, mesmo que com medo, acreditava que era uma situação provisória que não duraria muito e logo voltaria à normalidade. Quando conscientizaram que não havia previsão de término dessa situação, além do medo e da incerteza, surgiram tristeza, insegurança, desânimo e muita ansiedade. A quebra da rotina e das expectativas, a sensação de perda de controle, fizeram com que aparecesse muitos questionamentos sobretudo do futuro e muitos momentos de estagnação. A atividade física que no geral fazia parte dessa rotina deixou de ser, e a busca para outras alternativas de tentar manter o controle apareceram como yoga, meditação e outros afazeres que não faziam mais por falta de tempo, mas em sua maioria sem uma organização.

A última atividade de produção de texto foi novamente expressar o momento de cada um relacionado a rotina e ao COVID. Os integrantes produziram o texto sem rever o anterior e enviaram à equipe da Cia. Após o envio, deveriam reler o primeiro texto e fazer apontamentos de análise e comparação que foram posteriormente compartilhados no encontro virtual.

A nova análise ocorreu três meses depois do início da quarentena, cerca de 65 dias depois o primeiro texto. A insegurança e o medo permanecem, mas sob uma nova perspectiva, houve uma adaptação da situação e organização de uma nova rotina. O que não faziam antes por falta de tempo e inicialmente faziam como uma fuga, agora é realizado de forma consciente e proveitosa. Surgem novos experimentos e conhecimentos inéditos.

Um ponto relevante comentado por todos foi a questão de "olhar para si" e em todo o processo de se (re)inventar e se (re)conhecer realizaram uma conexão do físico e mental/espiritual, como forma de concentração para reorganizar a nova rotina, que as experimentações e estudos relacionados à Presença, auxiliaram nessa nova perspectiva. Novos sentimentos surgiram como saudade, paciência, 
esperança e coragem; e um novo mundo que parece ter dado uma desacelerada, com um olhar diferente e novas reflexões. Ao final de um dos textos foi feito um questionamento - "como obter algo em um ano que se tende a afirmar arruinado?".

Utilizando todas as ferramentas desenvolvidas nesse processo e para finalizar este tópico corporal, foi produzido um vídeo conectando a (re) descoberta da presença e do momento atual no cotidiano de cada integrante. Os movimentos foram gravados por cada bailarino em um ambiente específico de significado da nova rotina. Todos os movimentos foram utilizados das próprias dinâmicas do processo de forma individual ou coletiva. A música escolhida foi: - Oração ao tempo, composição de Caetano Veloso e interpretada por Maria Gadú- por conta dessa relação do tempo vivido de novas significações, mas não foi utilizada como base do movimento, que nesse caso foram relacionados aos sentimentos e sensações (Figura 3).

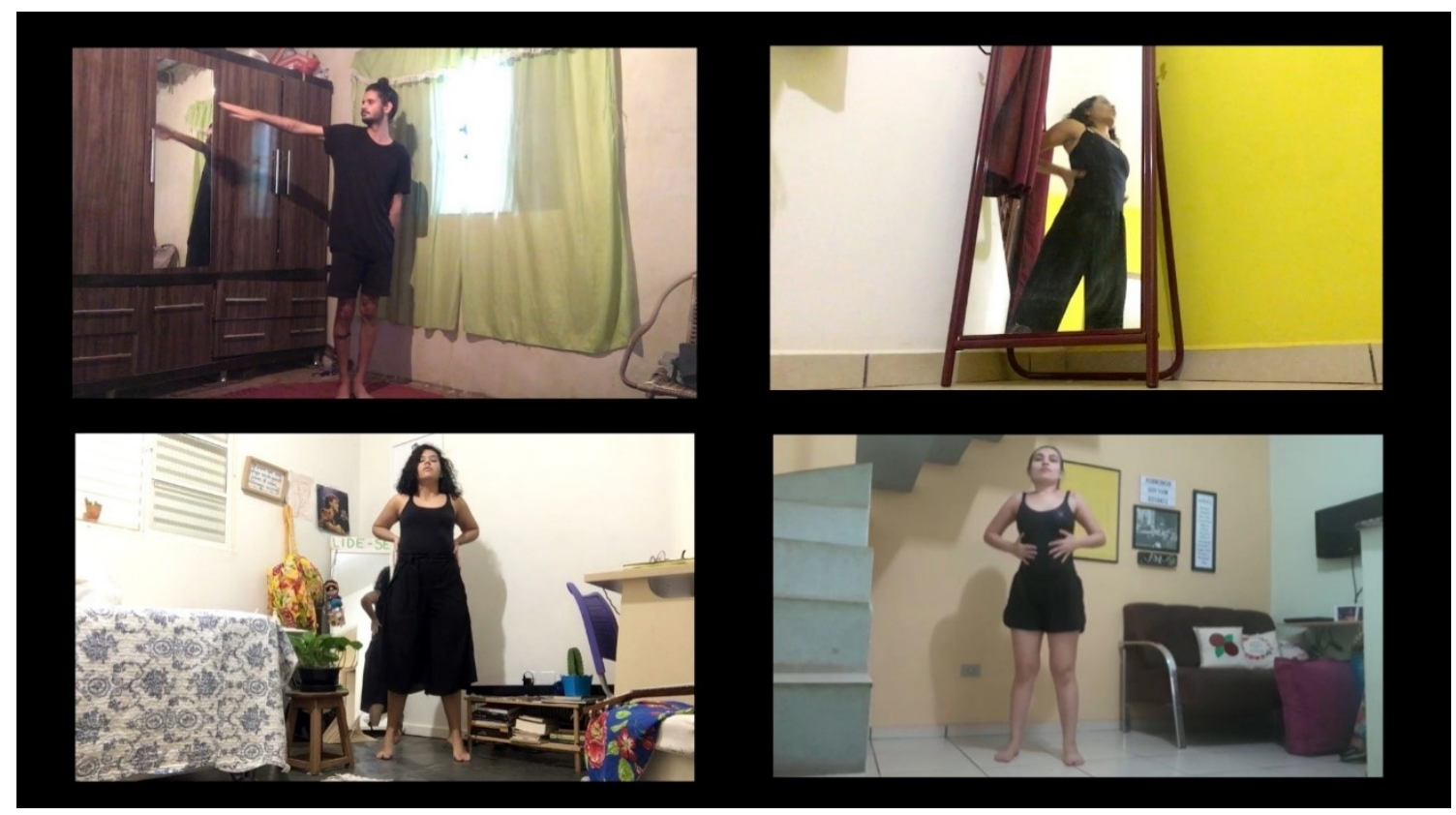

Figura 2 - Cena do vídeo Presença

Fonte: Arquivo da Cia UFMS, 2020.

Para essa criação foram necessários três momentos. O primeiro foi a gravação individual dos movimentos que foram apresentados e discutidos entre os integrantes. O segundo momento foi de gravar novamente pensando nas discussões do grupo e pensando na estética como roupa, maquiagem, a organização do espaço e iluminação. O último momento foi da edição em si utilizando as gravações específicas desse processo e algumas do trabalho ID.40. Foram quatro semanas do primeiro momento até a finalização do vídeo.

\section{Considerações finais}

Os desafios de pensar, sentir e mover o corpo de forma consciente e presente é um exercício diário e que muda constantemente pelos fatores variáveis como o tempo, o espaço e os sentimentos. O sujeito em sua busca descobre uma forma única de seu corpo, de seu movimento e suas aplicações. À vista disso é que a equipe da Cia. possui o interesse em se aprofundar na TKV, isto posto que não é uma técnica rígida e finita, e sim por proporcionar uma infinidade de possibilidades para um indivíduo, entre indivíduos, em qualquer ambiente. 
Os estudos iniciados em 2017 reafirmam e renovam conceitos, e a sua aplicabilidade corporal com a criação da Cia. demonstra que há um vasto campo a ser explorado e que fica em evidência com as adaptações realizadas para não parar o trabalho.

A presença como um despertar do corpo teve um novo significado pela nova estrutura de trabalho e principalmente de suporte para a nova adaptação cotidiana, desde o surgimento do Covid-19. Com a sua chegada e desestabilizando todas as sociedades do mundo, houve uma grande necessidade de adaptações. Ao se perceber em um espaço limitado e constante, alguns casos sozinhos, em outros administrando esse espaço e tempo com familiares, foi um desafio de análise, percepção e ação inicialmente apresentada pela dança, mas que se expandiu em cada momento a vivência do cotidiano.

Esse afastamento social fez com que todos os integrantes, bailarinos e equipe, aprendessem ou aprimorassem seu contato com as tecnologias. Antes da pandemia, o uso excessivo do celular era criticado por fazer as pessoas perderem o contato social, depois, virou a ferramenta fundamental para manter algum tipo de contato entre as pessoas.

Adaptar-se às tecnologias e ao espaço para trabalhar foram necessários para manter o trabalho corporal, mas os estudos teóricos foram fundamentais para entender os conceitos da TKV e a partir das leituras e discussões fazer as experimentações.

O ano de 2020 poderia ser visto como prejudicado ao se olhar para os planos e projeções que se almejava no início do ano. Pode ocorrer que o planejado não seja cumprido, mesmo com as modificações. Entretanto, ao se adaptarem os olhares pode-se ver novos planos, oportunidades inéditas, movimentos diferenciados, experiências e reflexões reformuladas, e (re)conhecer a importância de estar, viver e fazer presente do contexto, não importando as condições.

\section{Referências}

DUENHA, Milene Lopes; NUNES, Sandra Meyer. Presença que não se Faz Só: potências de afeto no ato de com-por entre corpos. Disponível em https://www.scielo.br/scielo.php?script=sci_arttext\&pid=S2237-26602017000100099. Acesso em 15 de maio de 2020.

MILLER, Jussara. A escuta do corpo: sistematização da técnica Klauss Vianna. São Paulo: Summus, 2007.

KATZ, Helena. Apresento. In: SANTANA, Ivani. Corpo aberto: Cunningham, dança e novas tecnologias. São Paulo: Educ, 2002.

SCHEIR, Ricardo. Dicas para anotar. In: NASSUR, Octávio. Culinária coreográfica: desmedidas de receitas para iniciantes na cozinha cênica. Santa Maria: Pallotti, 2012.

UFMS. Plano de contingência. Disponível em https://www.ufms.br/wpcontent/uploads/2020/03/Plano_Vs1-3.pdf. Acesso 15 de agosto de 2020.

UFMS. Plano de Contingência Universidade Federal de Mato Grosso do Sul COVID-19. Disponível:https://www.ufms.br/wp-content/uploads/2020/03/Plano_Vs1-3.pdf. Acesso 13 de agosto de 2020 .

SIGPROJ UFMS. Programa de Extensão Universitária. Cia de dança contemporânea da UFMS. Disponível em https://sigproj.ufms.br/. Acesso em 10 de agosto 2020.

WACHOWICZ, Fatima. Organismo dança contemporânea. In: XAVIER et al. (org.). Pesquisas em dança: Volume I. Joinville: Letradágua, 2008. 